\title{
Intracardiac rhabdomyoma in a newborn with tuberous sclerosis
}

\author{
I Kadek Suarca, Ida Bagus Agung Winaya, I Komang Kari
}

$\mathrm{P}$ rimary congenital cardiac tumors, especially intracardiac tumors, are rare in children. Rhabdomyoma is the most common one $e^{1,2}$ and usually diagnosed in the first few days of life. ${ }^{2}$ Referral from pediatric cardiac centers found that the incidence of cardiac tumors was $0.08 \%-0.20 \%$. Rhabdomyoma represents 36\%-42\% in autopsy series and $79 \%$ in clinical series. ${ }^{3,4}$

Rhabdomyoma is usually multiple and can involve myocardium, pericardium, papillary muscles, cardiac valve, pulmonary and aortic outflow tracts. ${ }^{3}$ This anomaly is actually a myocardial hamartoma rather than a true neoplasm. Although rhabdomyoma appears sporadically, $50-86 \%$ of the cases are associated with tuberous sclerosis (TS), $, 2,5$ an inherited autosomal dominant, especially in the presence of multiple tumors. ${ }^{6}$ Different organ systems may be affected giving various clinical manifestations, ${ }^{7}$ i.e, hamartomas in various organs, skin lesions, cerebral abnormalities (periventricular calcifications or nodules, seizures, cerebral atrophy), retinal phakomata, and renal angiomyolipomas. ${ }^{6,7}$ The clinical presentation of TS depends on the age of patient, organs involvement, and severity of involvement. The most common symptom is seizures. ${ }^{7}$ When the diagnosis has been established, genetic counseling is required for family members. ${ }^{7}$

The treatment of rhabdomyoma is usually conservative. ${ }^{6,8}$ Surgical intervention is restricted to cases with significant hemodynamic obstruction or lifethreatening arrhytmias. ${ }^{3,6}$ Seizure is managed by appropriate antiepileptic drugs; however it maybe unresponsive.

The prognosis depends on the number, size and location of the tumors as well as the presence or absence of associated anomalies. Cardiac dysrhythmias caused by compression of the conducting system are frequently identified. Rhabdomyoma grows slowly in utero but tends to regress spontaneously after birth.6,8 Previous reports emphasized a poor prognosis for fetuses or neonates with intracardiac rhabdomyomas. ${ }^{9}$ The mortality rate during the first week and first year of life are $33 \%$ and $80 \%$, respectively. Since approximately $60 \%$ of TS patients have asymptomatic rhabdomyomas, prognosis is variable. ${ }^{3}$

\section{Report of the case}

A term female baby was born to a 29-year-old $\mathrm{G}_{3} \mathrm{P}_{2} \mathrm{~A}_{0}$ mother by caesarian section at Sanglah Hospital, Denpasar, on November $25^{\text {th }}, 2004$. The birth weight

From the Department of Child Health, Medical School, Udayana University, Sanglah Hospital, Denpasar, Bali, Indonesia.

Reprint requests to: I Kadek Suarca MD, Department of Child Health, Medical School, Udayana University, Sanglah Hospital, Jalan Nias, Denpasar, Bali, Indonesia. Tel. 62-361-227911/227915, Ext. 128. Fax. $62-$ $361-244038$. 


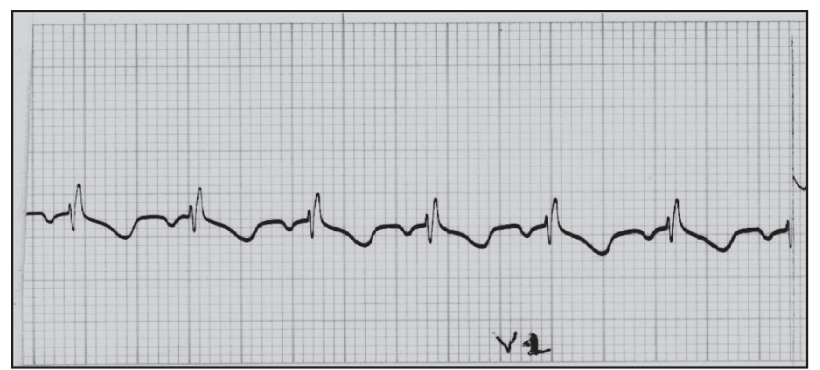

Figure 1. Electrocardiography ReVEaled RsR' in V1

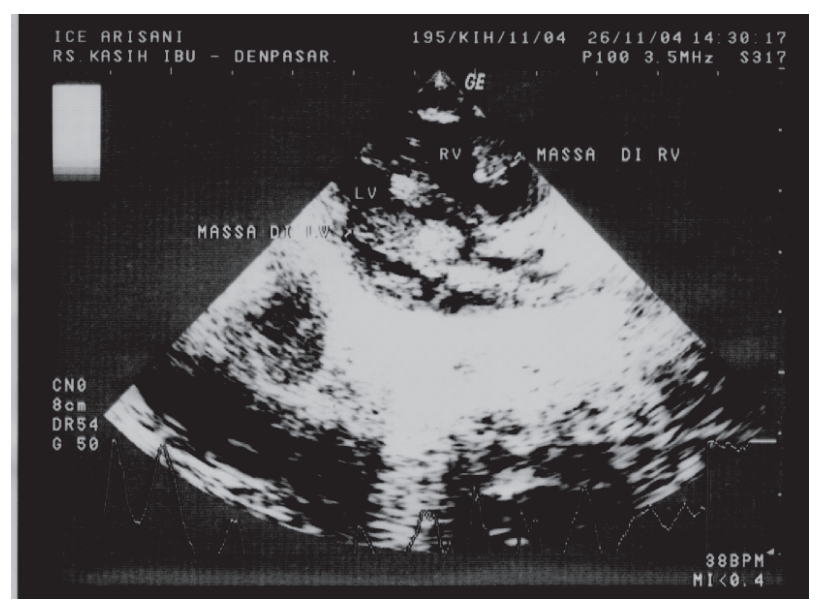

FIGURE 2. ECHOCARDIOGRAPHY SHOWED MASSES IN RIGHT AND LEFT VENTRICLE

was 3200 grams and she was a vigorous baby. Antenatal ultrasound at 30 weeks of gestation detected intracardiac masses suspected as intracardiac rhabdomyoma. There is no history or clinical signs of tuberous sclerosis in the mother or other members of the family.

On physical examination, she was a vigorous baby, no abnormalities was present and vital signs were within normal limits. On evaluation of the cardiovascular system, normal heart sound with regular heart rate was heard at 130/min and capillary refill was normal on four extremities. The only anomaly was on the skin, we found four hypopigmented macules on the left and right arm, leg, and on the back with the diameter varied from 4-8 $\mathrm{mm}$.

Routine laboratory findings showed leucocytes 11,800/ul, Hb 15.6 g/dl, Ht 44.6 vol\% and platelets count 332,000/ul. The AST was $49 \mathrm{IU} / 1$ and ALT was 12 IU/l. Chest X-ray showed normal heart and lung. The electrocardiography (Figure 1) revealed heart rate at 125/min, superior axis, rsR' on lead V1 (RBBB), and normal PR interval. Post natal cardiac ultrasonography revealed intracardiac mass in the right ventricle with the size of $17 \times 8 \mathrm{~mm}$. Echocardiography (Figure 2) showed normal chamber dimensions and anatomy, mobile multiple echogenic masses on systolic and diastolic phase in the left and right ventricle. The mass did not protrude into the ventricular out flow tract.

Based on these data the provisional diagnosis was suspected intracardiac rhabdomyoma associated with tuberous sclerosis.

The mother and father had neither symptom nor signs of TS. The baby had multiple hypopigmented patches under Wood's lamp examination. Ultrasound of kidney and liver were normal. Funduscopy found that the retina were normal. The infant's cardiovascular and respiratory state remained stable with no evidence of arrhythmia so she was subsequently discharged.

Follow up at the pediatric outpatient clinic included examination for further clinical manifestations of TS and serial echocardiography to evaluate tumors size. At 1 month of age, a CT-scan examination was planned to find sign of cortical tuberous sclerosis but her parents refused. At the age of 4 months, she had tonic clonic seizures of 5 minutes duration, twice within 24 hours without fever and we diagnosed it as non febrile convulsion. CT-scan (Figure 3) showed multiple periventricular calcifications. The electroencephalo-

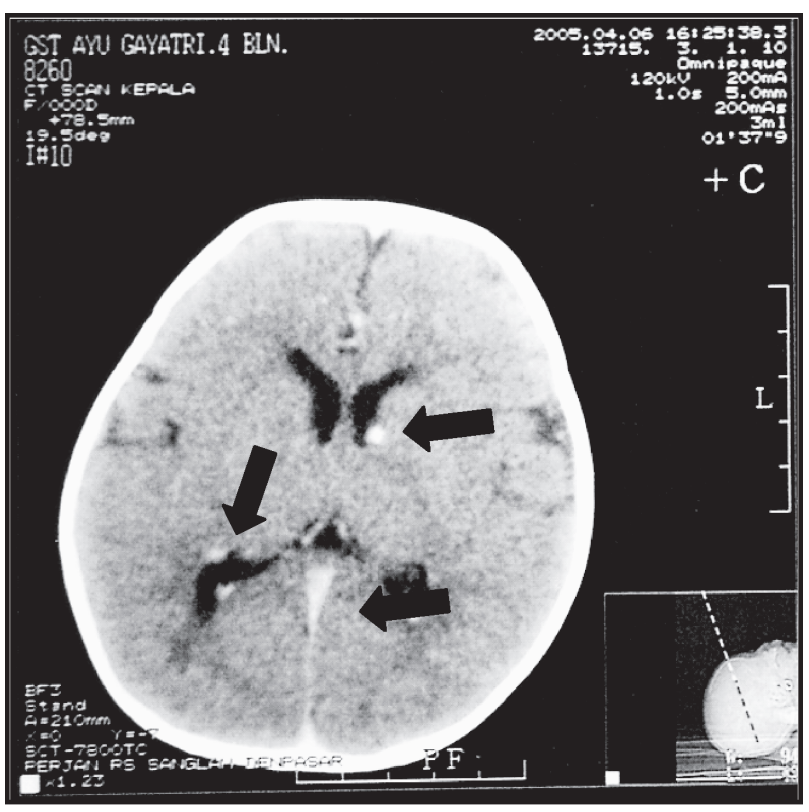

Figure 3. SKULL CT-SCAN REVEALED MULTIPLE PERIVENTRICULAR CALCIFICATIONS 
graphy revealed normal limit background with centrospike. Cardiac sonography at that time showed the tumor still persisted with the size of $17 \times 7.9 \mathrm{~mm}$.

Our final diagnosis was suspected intracardiac rhabdomyoma associated with tuberous sclerosis.

\section{Discussion}

Neonatal cardiac tumors are rare entities. Autopsy series in children reported an incidence of $0.027-$ $0.08 \%$. Boston Children's Hospital found the incidence of $0.17 \%$. While symptomatic rhabdomyoma in the United Kingdom has been estimated to be 1 in $326,000.10$ We have no data in Indonesia and our case is the first case hospitalized at Sanglah Hospital, Denpasar. Rhabdomyomas are generally multiple and well-circumscribed tumors. They can occur anywhere in the heart, most commonly in the ventricles. They can be intramural or pedunculated and encroaching on the intracavity space. They are non malignant hamartomas. ${ }^{1}$ They may be detected during prenatal period on a routine fetal ultrasound or may present as hydrops foetalis. ${ }^{1,9,10}$ If a single intracardiac tumor is demonstrated, the most likely diagnosis is rhabdomyoma. Other causes such as fibroma, teratoma, and myxoma, $3,8,11,12$ differ both clinically and ultrasonographically. ${ }^{12}$ In adults, intracardiac myxoma as the most common type of primary cardiac tumor is usually located in the left atrium and/or the inter atrial septum. ${ }^{3}$ As most rhabdomyomas are multiple, the diagnosis is generally beyond doubt, and may be made even in the absence of histopatologic confirmation. ${ }^{9,12}$

In this case, the tumor was located on the right and left ventricle and found during antenatal period at 30 weeks of gestation. Intracardiac rhabdomyoma was confirmed on echocardiography after birth.

The variety of clinical symptoms of cardiac rhabdomyomas depends on their number, size and position. ${ }^{1,3,12-14}$ Postnatally, they may be asymptomatic or may present as asymptomatic cardiac murmur, congestive cardiac failure with low cardiac output due to intracardiac flow obstruction, ${ }^{10-14}$ arrhythmias of various types ${ }^{1,3,0,14}$ or as infant sudden death. . $^{1,3,4,12}$ The dysrhythmias associated with rhabdomyomas were usually supraventricular tachycardia, Wolff-ParkinsonWhite syndrome, atrial flutter and fibrillation, variable atrioventricular block, ectopic atrial tachycardias, premature extrasystoles, and ventricular tachycardia. Two theories have been proposed regarding the development of these dysrhythmias. First theory proposes that rhabdomyomas consist of an overgrowth of Purkinje cells and capable for impulse conduction. ${ }^{3}$ Second theory is a more common hypothesis. Arrhytmias are the result of disruption of conduction tissue by tumor growth within the intraventricular septum. 3,6

In our case, the tumors were multiple and mobile, located on the right and left ventricle, and not protruding into the ventricular out flow tract so there was no disturbance of intracardiac blood flow. The tumor size was not large enough to cause total compression of the conducting system but the tumor on right ventricle might cause delayed depolarization resulting in RBBB on ECG. Overall, these rhabdomyomas were asymptomatic.

Cardiac rhabdomyomas are strongly associated with tuberous sclerosis. It is estimated that $50-60 \%$ of tuberous sclerosis patients will develop cardiac rhabdomyomas. Conversely, $51-86 \%$ of rhabdomyomas are reported to be associated with TS. ${ }^{1,10}$ The characteristic features consist of major and minor features. The major features are facial angiofibromas or forehead plaque, non-traumatic ungual or periungual fibromas with at least 3 hypomelanotic macules, shagreen patch (connective tissue naevus), multiple retinal nodular hamartomas, cortical tuber, subependymal nodule, sub-ependymal giant cell astrocytoma, cardiac rhabdomyoma, single or multiple lymphangiomyomatosis, and renal angiomyolipoma. The minor features are multiple randomly distributed pits in dental enamel, hamartomatous rectal polyps, bone cysts, cerebral white matter radial migration lines, gingival fibromas, nonrenal hamartoma, retinal achromic patch, confetti skin lesions, and multiple renal cysts. ${ }^{3,15}$ Definite tuberous sclerosis is diagnosed by either 2 major features or 1 major feature and 2 minor features. Probable tuberous sclerosis is suggested by 1 major feature and 1 minor feature while possible tuberous sclerosis is either 1 major feature or 2 or more minor features. ${ }^{15} \mathrm{CT}$-scan has a diagnostic accuracy approaching $90 \%$ and can demonstrate cerebral hamartomas, subependymal tumors, ventriculomegaly, and areas of diffuse demyelinisation. Mineralization of hamartomas may occur as early as 1 month of age. TS does not have any typical EEG feature. 
In our patient, TS was established by the presence of cardiac rhabdomyoma, 4 hypomelanotic macules, and multiple periventricular calcification on CT-scan. The normal result on EEG examination is not an indicator of prognosis.

Seizures is the most common symptom of TS and they can appear at any time after birth. ${ }^{7,15}$ Epilepsy affects $70 \%$ of the cases and often starts with "salaam fit's" in infancy. ${ }^{15}$ The seizures is managed by administering appropriate anti epileptic drugs. $7,15,16$

In this case, the first seizure occurred at 4 months of age, twice within 24 hours for 5 minutes each time. There was no seizure until now. We diagnosed as non febrile convulsion and antiepileptic drugs were not given.

Tuberous sclerosis is inherited as a single gene with an autosomal dominant pattern caused by spontaneous mutation. ${ }^{3}$ There are two distinct genes involved, $\mathrm{TSC}_{1}$ and $\mathrm{TSC}_{2}{ }^{3}{ }^{3,17-19}$ The genes are located on chromosomes 9 and 16. Both genes have been identified as tumor suppressor genes. It explains why they produce identical phenotypes i.e the formation of multiple hamartomas. ${ }^{10,17,19}$ Genetic testing is not available because of the genetic heterogenicity of the TSC and the wide variety of mutations. ${ }^{18}$ If any fetus is discovered to have a cardiac tumor, a careful pedigree analysis for TS should be done. ${ }^{20}$ Since there was no history or clinical signs of TS in the pedigree of our patient, we concluded that her gene changes were caused by mutations.

The value of surgical resection for symptomatic tumors i.e to remove obstruction or an arrhythmogenic substrate, is well established ${ }^{3,12,14}$ but is neither possible nor indicated in every child. ${ }^{2,21}$ Unless critical obstruction or dysrhythmias occurs, conventional approach is preferred. Spontaneous regression does not depend on the initial size, number, or location of tumors. Partial or complete spontaneous regression of rhabdomyomas has been reported in $54 \%$ of cases. ${ }^{1,2}$ Regression may take place in a period as short as three weeks ${ }^{13}$ and may also persist in adult. ${ }^{4}$ Echocardiography is useful to determine the size, number and location and also to evaluate the hemodynamic consequence of the tumors. Serial echocardiographic studies are both useful and safe in monitoring tumor size and they provide acceptable follow-up information. ${ }^{13}$

Concerns regarding long-term outcome are mainly focused on the development and health consequences of TS. $3,7,17,18$ Generally, the earlier the onset of seizures, the greater the likelihood of mental retardation. ${ }^{3,17}$ Reoccurring seizures is usually recalcitrant to treatment. ${ }^{7}$

Our case showed asymptomatic intracardiac tumor which does not need surgical intervention. Occurrence of seizure in early life may lead to poor prognosis. Attention to monitor developmental disorder will be required.

\section{Acknowledgements}

We are grateful to Tjok Suwardewa, MD for his support to follow up this case from antenatal period.

\section{References}

1. Marx GR, Moran AM. Cardiac tumors. In: Allen HD, Clark EB, Gutgesell HD, Driscoll DS, editors. Moss and Adams' heart disease in infant, children and adolescents. 6th ed. Philadelphia: Lippincott Williams and Wilkins; 2000. p. 1432-45.

2. Dalvi R, Vernekar J, Godinho S, Kartha R. Cardiac rhabdomyoma-antenatal diagnosis. In J Radiol Imag 2002;12:339-40.

3. Bianchi DW, Crombleholme TM, Dalton ME. Rhabdomyoma. In: Bianchi DW, Crombleholme TM, Dalton ME, editors. Fetology diagnosis and management of the fetal patient. New Yorks: McGrawHill; 2000. p. 409-15.

4. Pipitone S, Mongiovi M, Grillo R, Gagliano S, Sperandeo V. Cardiac rhabdomyoma in intrauterine life: Clinical features and natural history a case series and review of published Reports. Ital Heart J 2002;3:48-52.

5. Meyer WJ, Gauthier DW, Font G. Cardiac Rhabdomyoma. The fetus net (serial online) Last update 16 September 1993 (cited 30 November 2004). Available from: URL: http://www.thefetus.net/page.php?id=506

6. Lantin RL. Cardiac manifestations in people with tuberous sclerosis complex. Factsheet tuberous sclerosis alliance (serial online). Available from: URL: http:// www.tsalliance.org.

7. Berg BO. Neurocutaneous syndromes phakomatoses and allied conditions. In: Kenneth F, Swaiman, editors. Pediatric neurologic principles and practice. USA: The CV Mosby Company; 1999. p. 795-813. 


\section{Paediatrica Indonesiana}

8. Shapiro LM. Cardiac Tumours: Diagnosis and management. Heart 2001;85:218-22.

9. Dolkart LA, Reimers FT, Finnerty TC, Botti JJ, Weber HS. Cardiac rhabdomyoma. The fetus net. Last update 6 November 1993 (cited 13 April 2005). Available from: URL: http://www.thefetus.net/page.php?id $=38$.

10. Webb DW, Thomas RD, Osborne JP. Cardiac rhabdomyomas and their association with tuberous sclerosis. Arch Dis Child 1993;68:367-70.

11. Malisch TW, Jeanty P. Cardiac Fibroma. The Fetus net. Last update 19 January 1991 (cited 25 November 2004). Available from: URL: http://www.thefetus.net/ page.php?id=56.

12. Batmaz G, Besikci R, Arslan G, Kafadar I, Ahunbay G. Spontaneous regression of huge cardiac rhabdomyoma in an infant. Images Paediatr Cardiol 2000;5:4-10.

13. Erdem S, Kucukosmanoglu O, Salih OK, Erdogan S, Tunali N, Ozbarlas N. A Case report rhabdomyoma caused right ventricular outflow tract obstruction in an infant. Anadolu Kardiyol Derg. 2003;3:171-3.

14. Ibrahim CPH, Thakker P, Miller PA, Barron D. Cardiac rhabdomyoma presenting as left ventricular outflow tract obstruction in a neonate. Interactive cardiovasc and thorac surg 2003;2:572-4.
15. Hewish P. Tuberous sclerosis. Patient plus. Last update 24 November 2004 (cited 10 April 2005). Available from: URL: http://www.patient.co.uk/showdoc/ 40001784.

16. O'Callaghan FJK, Clarke AC, Joffe H, Keeton B, Martin $\mathrm{R}$, Salmon A, et al. Tuberous sclerosis complex and Wolff-Parkinson-White syndrome. Arch Dis Child 1998;78:159-62.

17. O'Callaghan FJK, Osborne JP. Recent advances: Advances in the understanding of tuberous sclerosis. Arch Dis Child 2000;83:140-2.

18. Levine D, Barnes P, Korf b, Edelman R. Tuberous sclerosis in the fetus: Second-trimester Diagnosis of subependymal Tubers with Ultrafast MR Imaging. Am J Radiol 2000;175:1067-9.

19. Slegtenhorst M, Nellist M, Nagelkerken B, Cheadle J, Snell R, OuwelandAVD, et al. Interaction between Hamartin and Tuberin, the TSC1 and TSC2 Gene Products. Hum Mol Genet 1998;7:1053-7.

20. Manikoth P, Leanage R, Valliattu J, Khusaiby SMA. Cardiac tumour in neonate with left ventricular outflow tract obstruction. Heart 2004;90:877-81.

21. Stiller B, Hetzer R, Meyer R, Dittrich S, Pees C. Primary cardiac tumours: When is surgery necessary. Eur J Cardiothorac Surg 2001;20:1002-6. 